\title{
GENT2: an updated gene expression database for normal and tumor tissues
}

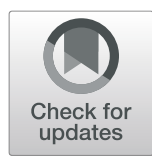

\author{
Seung-Jin Park ${ }^{1,2}$, Byoung-Ha Yoon ${ }^{1,2}$, Seon-Kyu Kim ${ }^{3^{*}}$ and Seon-Young Kim ${ }^{1,2^{*}}$ \\ From The 8th Annual Translational Bioinformatics Conference \\ Seoul, South Korea. 31 October - 2 November 2018
}

\begin{abstract}
Background: Gene Expression database of Normal and Tumor tissues 2 (GENT2) is an updated version of GENT, which has provided a user-friendly search platform for gene expression patterns across different normal and tumor tissues compiled from public gene expression data sets.

Results: We refactored GENT2 with recent technologies such as Apache Lucene indexing for fast search and Google Web Toolkit (GWT) framework for a user-friendly web interface. Now, GENT2 contains more than 68,000 samples and has several new useful functions. First, GENT2 now provides gene expression across 72 different tissues compared to 57 in GENT. Second, with increasing importance of tumor subtypes, GENT2 provides an option to study the differential expression and its prognostic significance based on tumor subtypes. Third, whenever available, GENT2 provides prognostic information of a gene of interest. Fourth, GENT2 provides a meta-analysis of survival information to provide users more reliable prognostic value of a gene of interest.
\end{abstract}

Conclusions: In conclusion, with these significant improvements, GENT2 will continue to be a useful tool to a wide range of researchers. GENT2 is freely available at http://gent2.appex.kr.

Keywords: Tissue and cell line wide gene expression profiling, Cancer subtype profiling, Survival analysis, Meta-survival analysis, Large scale microarray web-database

\section{Background}

The explosion of publicly available omics datasets including gene expression microarray and next-generation sequencing has provided valuable resources for researchers. However, for most researchers with few bioinformatics skills, public datasets in a raw data format are of little value. To help researchers to utilize public gene expression datasets, we previously developed a web-based gene expression database named Gene Expression database of Normal and Tumor tissues (GENT) [1]. GENT provides gene expression profiles across diverse human cancer and normal tissues with

\footnotetext{
*Correspondence: seonkyu@kribb.re.kr; kimsy@kribb.re.kr

${ }^{3}$ Personalized Genomic Medicine Research Center, KRIBB, Daejeon 34141, Korea

${ }^{1}$ Genome Editing Research Center, Korea Research Institute of Bioscience and Biotechnology (KRIBB), Daejeon 34141, Korea

Full list of author information is available at the end of the article
}

more than 34,000 samples generated by the Affymetrix U133A or U133Plus2 microarray platform with consistent data processing. To our satisfaction, since its launch at 2011, GENT has been widely used by researchers across the world, with over 1600 visitors per month on average, and the method has been cited more than 100 times in research work [2-6].

In our opinion, a few strengths have contributed to the success of GENT. First, it is very simple to use. A user inputs a gene symbol of interest and gets back results within a few seconds. Second, the large amounts of samples $(\sim 34,000)$ generated using the same platform with consistent data processing makes the database reliable by removing or reducing many biases (i.e., different batches, laboratories, ethnicities, etc.) caused by a small sample size. Third, GENT provides intuitive graphics as well as raw gene expression values to users, so users can utilize the information in convenient ways. 
Enormous amounts of publicly available gene expression datasets have accumulated since GENT was first published in 2011, and the need was recognized to upgrade the GENT system both quantitatively and qualitatively. Here, GENT2 is provided as an updated version of GENT with more samples and newer functionalities. Major improvements of GENT2 over GENT are the following. First, GENT2 contains more than 68,000 samples compared to 34,000 samples in GENT. Second, GENT2 provides gene expression information on 72 paired tissues compared to 57 tissues of GENT. Third, GENT2 provides results of statistical tests (t-test, log2 fold changes, etc.) as well as boxplot summaries for user convenience. Fourth, considering the importance of tumor subtypes, GENT2 provides results of various cancer subtype profiling analysis (e.g., stage or grade with various molecular subtypes), Fifth, it provides results of prognostic value estimation using Kaplan-Meier plots. Finally, GENT2 provides results of meta-survival analysis combining various independent studies for reliable prognostic information. With these significant improvements, GENT2 is suggested as a versatile tool to assess the biological and prognostic relevance of a specific gene in various cancers.

\section{Construction and content}

To construct the GENT2 system, gene expression data is downloaded from the NCBI GEO database generated by two microarray platforms (Affymetrix U133A or U133Plus2). Then, the data were stratified into cancer and normal samples across 72 tissues. The GENT2 database provides the following five functions: 1) a landscape of gene expression profile across 72 normal and tumor tissues, 2) cancer subtype profiling, 3) statistical significance of gene expression difference between normal and tumor samples, 4) a prognostic value of gene expression, and 5) meta-survival analysis (Fig. 1). The following sections present the workflows of how the database was constructed.

\section{Collection and processing of publicly available gene expression datasets}

We collected data from the NCBI GEO public database and processed them with the MAS5 algorithm using the affy package in Bioconductor [7]. We used the same MAS5 algorithm used in the original GENT, as it is a single-array algorithm, which allows the comparison of multiple independent datasets [1].

\section{GENT2 implementation}

The GENT2 system consists of the following two main parts: indexed DB and web-based user interface. To construct a database that can handle a huge gene expression profile (over 68,000 cancer patients) efficiently, we applied the Apache Lucene index machine (ver. 7.4.0) into whole gene expression datasets. A web-based graphical user interface (GUI) was implemented with the Google Web Toolkit (GWT, ver. 2.7.0) and GWT extended (GXT, ver. 4.0.0) frameworks based on JAVA language. Data exchange between a web browser and the GENT2 server is controlled by a GWT remote

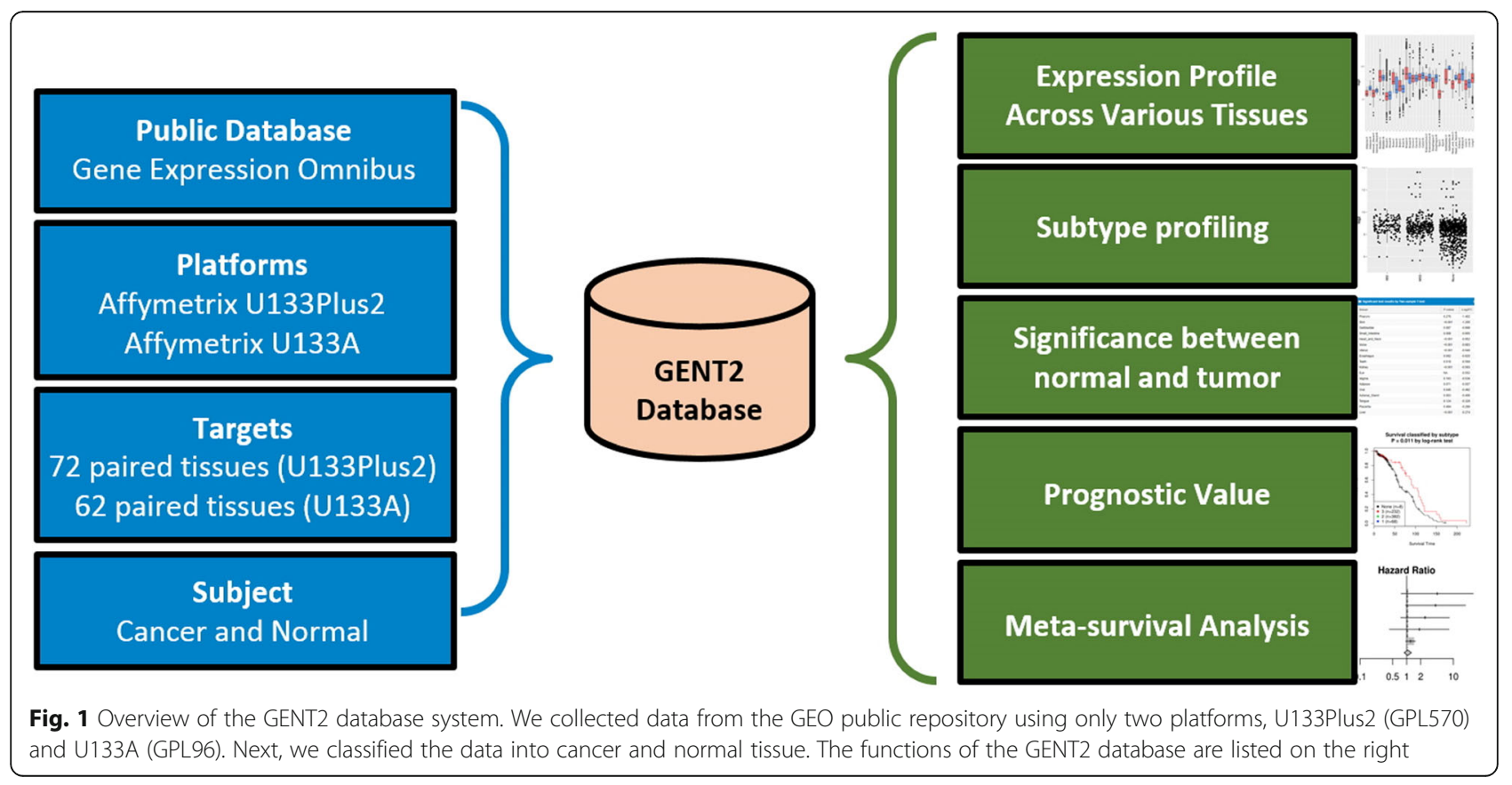


Table 1 GENT2 database description

\begin{tabular}{|c|c|c|c|c|c|c|}
\hline & \multicolumn{3}{|l|}{ GENT } & \multicolumn{3}{|l|}{ GENT2 } \\
\hline & U133Plus2 (GPL570) & U133A (GPL96) & Total & U133Plus2 (GPL570) & U133A (GPL96) & Total \\
\hline Datasets & 306 & 241 & 547 & 887 & 358 & 1245 \\
\hline Samples & 24,300 & 16,400 & 40,700 & 44,857 & 23,283 & 68,140 \\
\hline Probes & 54,613 & 22,215 & & 54,613 & 22,215 & \\
\hline
\end{tabular}

The GENT2 DB contains 887 (U133Plus2) and 358 (U133A) datasets, which contain more than 44,000 patient data records and more than 23,000 patient data records, respectively. The U133Plus2 platform is the most used in Gene Expression Omnibus (GEO)

procedure call. All statistical tests provided from the GENT2, such as two-sample t-test, Kaplan-Meier with log-rank test, and meta-survival analysis with Cox proportional hazard modes, were implemented using $\mathrm{R}$ (ver. 3.2.5) with Bioconductor plugins (ver. 3.6). The system architecture of GENT2 is illustrated in Additional file 3: Figure S1.

\section{Database description}

GENT2 contains more than 44,000 (U133Plus2; 887 datasets) and 23,000 (U133A; 358 datasets) samples (Table 1, Additional file 1: Table S1, Additional file 2: Table S2). A larger number of samples were added to the original GENT, and over 380 datasets were added for the U133Plus2 platform. The top three tissues of each platform are as follows: blood, brain and breast for U133Plus2 and blood, bone marrow and brain for U133A. Additionally, subtype analysis and meta-analysis data in GENT2 are displayed in Tables 2 and 3, respectively.

\section{Utility}

Tissue- and cell line-wide expression profile comparing normal and tumor samples

When a user puts a gene symbol in the 'Search Gene profile' page, GENT2 performs tissue-wide expression profiling and statistical testing quickly (less than $5 \mathrm{~s}$ ) on

Table 2 Subtypes of each cancer type

\begin{tabular}{|c|c|c|c|c|c|}
\hline Tissue & Subtypes & Samples & Tissues & Subtypes & Samples \\
\hline Adrenal Gland & Grade & 29 & Liver & Stage & 80 \\
\hline Bladder & $\begin{array}{l}\text { Stage } \\
\text { Grade }\end{array}$ & 93 & Lung & $\begin{array}{l}\text { Molecular Subtype } \\
\text { Stage } \\
\text { Histology }\end{array}$ & 1074 \\
\hline Blood & $\begin{array}{l}\text { Cancer } \\
\text { Molecular Subtype } \\
\text { Stage }\end{array}$ & 5924 & Oral & Stage & 74 \\
\hline Brain & $\begin{array}{l}\text { Cancer } \\
\text { Grade } \\
\text { Histology }\end{array}$ & 2168 & Ovary & $\begin{array}{l}\text { Stage } \\
\text { Grade } \\
\text { Histology }\end{array}$ & 940 \\
\hline Breast & $\begin{array}{l}\text { Molecular Subtype } \\
\text { ER status } \\
\text { PR status } \\
\text { HER2 status } \\
\text { Grade } \\
\text { Histology } \\
\text { Histology Group }\end{array}$ & 1246 & Pancreas & $\begin{array}{l}\text { Stage } \\
\text { Grade }\end{array}$ & 70 \\
\hline Cervix & $\begin{array}{l}\text { Stage } \\
\text { Histology }\end{array}$ & 89 & Prostate & Gleason Grade & 46 \\
\hline Colon & $\begin{array}{l}\text { Molecular Subtype } \\
\text { AJCC Stage } \\
\text { Duke Stage } \\
\text { Grade } \\
\text { Histology }\end{array}$ & 1146 & Skin & Stage & 123 \\
\hline Endometrium & $\begin{array}{l}\text { Stage } \\
\text { Grade } \\
\text { Histology }\end{array}$ & 91 & Stomach & $\begin{array}{l}\text { Molecular Subtype } \\
\text { TNM Stage } \\
\text { Lauren Classification }\end{array}$ & 300 \\
\hline Head and Neck & Stage & 24 & Thyroid & $\begin{array}{l}\text { Cancer } \\
\text { Stage }\end{array}$ & 204 \\
\hline Kidney & $\begin{array}{l}\text { Cancer } \\
\text { Stage }\end{array}$ & 182 & & & \\
\hline Total & & & & & 13,903 \\
\hline
\end{tabular}


Table 3 Datasets used with meta survival analysis in GENT2

\begin{tabular}{|c|c|c|c|c|}
\hline \multirow[t]{2}{*}{ Tissue } & \multicolumn{3}{|c|}{ Prognosis Types } & \multirow[t]{2}{*}{ Datasets } \\
\hline & $\overline{O S}$ & PFS & RFS & \\
\hline Adrenal Cortex & 0 & & & 3 \\
\hline Bladder & O & & $\mathrm{O}$ & 4 \\
\hline Blood & $\mathrm{O}$ & & & 5 \\
\hline Bone & $\mathrm{O}$ & & & 5 \\
\hline Bone Marrow & $\mathrm{O}$ & & O & 16 \\
\hline Brain & $\mathrm{O}$ & & & 11 \\
\hline Breast & $\mathrm{O}$ & $\mathrm{O}$ & $\mathrm{O}$ & 53 \\
\hline Bronchus & O & & & 1 \\
\hline Colon & O & & $\mathrm{O}$ & 20 \\
\hline Fibrous & & & $\mathrm{O}$ & 1 \\
\hline Head And Neck & & & O & 1 \\
\hline Kidney & $\mathrm{O}$ & & & 1 \\
\hline Larynx & & & $\mathrm{O}$ & 1 \\
\hline Liver & O & & & 2 \\
\hline Lung & O & $\mathrm{O}$ & $\mathrm{O}$ & 26 \\
\hline Lymph & $\mathrm{O}$ & & O & 4 \\
\hline Merkel Cell & O & & & 1 \\
\hline Mouth(Tongue) & $\mathrm{O}$ & & & 1 \\
\hline Myeloid Cell & O & & & 8 \\
\hline Neural Crest & $\mathrm{O}$ & & & 1 \\
\hline Ovary & O & O & $\mathrm{O}$ & 20 \\
\hline Pancreas & $\mathrm{O}$ & & & 2 \\
\hline Prostate & $\mathrm{O}$ & & & 2 \\
\hline Sarcoma & O & & & 1 \\
\hline Skin & O & & & 3 \\
\hline Stomach & O & & & 1 \\
\hline Thyroid & O & & & 1 \\
\hline Total & & & & 195 \\
\hline
\end{tabular}

OS Overall Survival, PFS Progression-Free Survival, RFS Recurrence-Free Survival

two Affymetrix platforms, simultaneously. 'Search Gene profile' provides two boxplots of gene expression from the Affymetrix U133Plus2 and the Affymetrix U133A platform, allowing users to compare both results. In Fig. 2a, for example, we illustrate the tissue-wide gene expression profile of an oncogene, ERBB2. Compared to normal, ERBB2 was overexpressed in a few tumors including from bone, breast, and ovary. The t-test (Fig. 2b) shows that there were significant expression differences between tumor and normal tissues in bone, breast and ovary tissues (3.9-fold and $P<0.001,1.9$-fold and $P<0.001,1.9$-fold and $P<0.001$, respectively). ERBB2 is a representative oncogene activated in breast cancer [8]. It was also reported that ERBB2 overexpression helps metastatic progression of prostate cancer to bone [9]. Moreover, ovarian cancer was also linked to $E R B B 2$ activation, and many efforts are on-going to develop molecular cancer therapeutics by targeting the $E R B B 2$ pathway.

\section{Subtype profiling with survival analysis}

In GENT2, we added the following two novel functions: subtype profiling and survival analysis. If a user selects a tissue and a specific subtype, GENT2 provides the expression profiling of subtypes of the selected tissue. In addition, it provides results of a statistical test (ANOVA or t-test) and survival analysis on the subtype. For instance, the expression pattern for the molecular subtype of the ERBB2 gene in breast cancer tissue is shown in Fig. 3a. As expected, the HER2 group has the highest value on average, and the TNBC group has the lowest value. Statistical tests are also performed for each subtype (Fig. 3b). In particular, the ERBB2 gene has a highly distinct expression pattern with relatively all significant differences in each group. Finally, survival analysis is performed for each subtype (Fig. 3c). Although the ERBB2 gene showed distinct expression patterns, the log-rank test $p$-value for each group was found to be insignificant, suggesting that expression difference is irrelevant of prognostic difference. Currently, a subtype analysis function provides information on 46 subtypes of 19 tissue types with over 13,000 samples.

\section{Meta-survival analysis}

Confirming the prognostic relevance of a gene is important for its application in the clinical field. Many studies have reported incongruent prognostic characteristics of a gene, thus there is a great need to further evaluate the prognostic potential of a gene by combining multiple information across many studies. Hence, we adopted a meta-survival analysis into GENT2, providing reliable prognostic power estimated by synergetic effect across many independent reports. This allows integrated statistical analysis from different studies, which greatly increases the number of samples and improves statistical power. For example, progression-free survival in breast tissue for the $E R B B 2$ gene was analyzed by meta-analysis (Fig. 4). The top six datasets indicate that the hazard ratios are over 1 for the same gene and the same tissue region (breast), while others show the hazard ratios under 1. This result suggests that the prognostic value of ERBB2 can be different according to different contexts. For example, the GSE9195 dataset is an experiment to identify the effect of tamoxifen in estrogen receptor positive $(E R+)$ breast cancer [10], while the GSE16446 dataset is also an experiment to uncover the effect of anthracycline in estrogen receptor negative (ER-) breast cancer [11]. We suggest that 

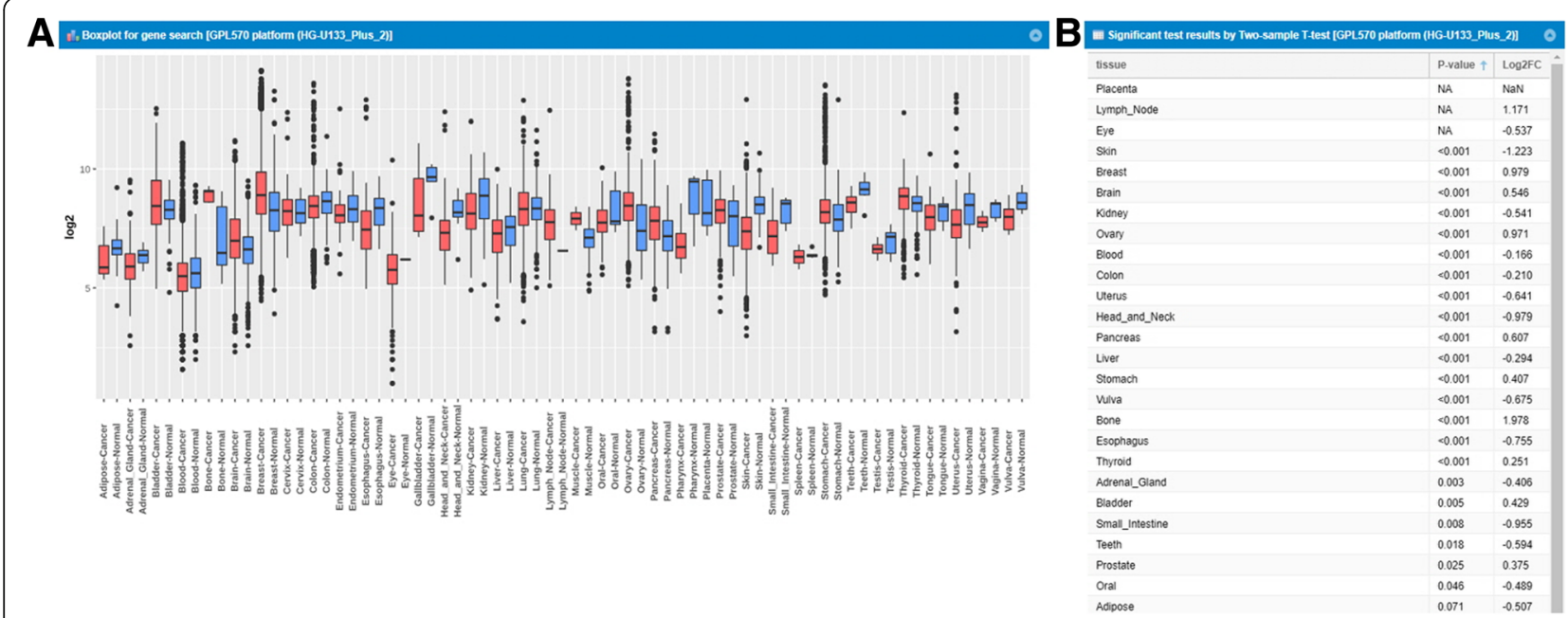

Fig. 2 Tissue-wide gene expression pattern of ERBB2 gene across 72 paired tissues and statistical tests. a A boxplot across 72 paired tissues in GPL570 only. Red indicates a boxplot of cancer samples. Blue indicates a boxplot of normal samples. We exclude the tissue-wide boxplot of GPL96. $\mathbf{b}$ Statistical test based on expression profile at each tissue. For each tissue, $P$-value and log2 fold change are calculated, and NA at the ' $P$ value' column means that there is only one sample of normal tissue. Same above, the statistical test of GPL96 has been excluded

comparing multiple datasets researchers can obtain more reliable prognostic information.

\section{Performance improvements by technological updates}

In the previously constructed GENT, all search and display activities were implemented using PHP and MySQL environments. PHP is one of the widely used computational languages on the server side and MySQL is an open-source relational database management system that stores the large amounts of data. Upon exponentially increased gene expression data that are publicly available, there has been a great need to upgrade system architecture of the GENT to efficiently handle those huge data sets. Thus, we applied recent informatics technologies including GWT and Lucene into the GENT2.
By using GWT framework, user-friendly and flexible web interfaces were equipped in the GENT2, and real-time interactions between web-client and server systems through GWT RPC method were also available. Especially, applying Lucene index machine, a high-performance information retrieval library, into the GENT2, ultra-fast access across enormous expression data from more than 68,000 samples is available. Compared with MySQL system, Lucene indexing in the GENT2 showed a better performance accessing faster than approximately 10 times.

\section{Discussion}

Many databases have been developed that show gene expression of cancer samples. For instance, Oncopression

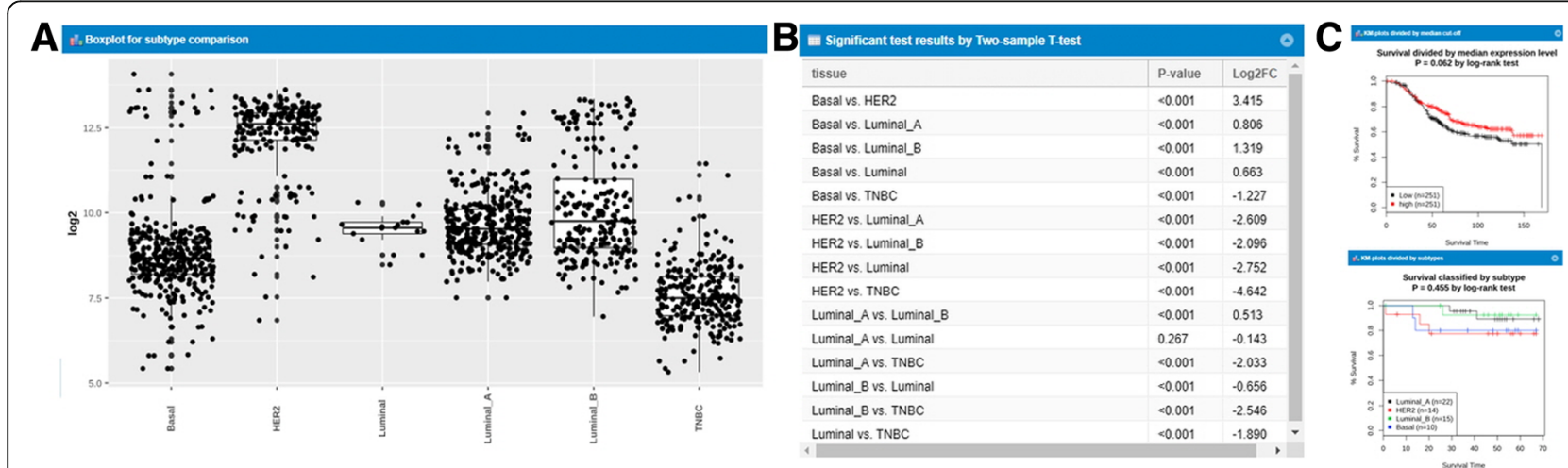

Fig. 3 Subtype and survival analysis. a Box and dot-plot of each subtype. b Statistical test based on each subtype. For each subtype, P-value and $\log 2$ fold change are calculated. c Kaplan-Meier plots by subtypes and median cut-off 


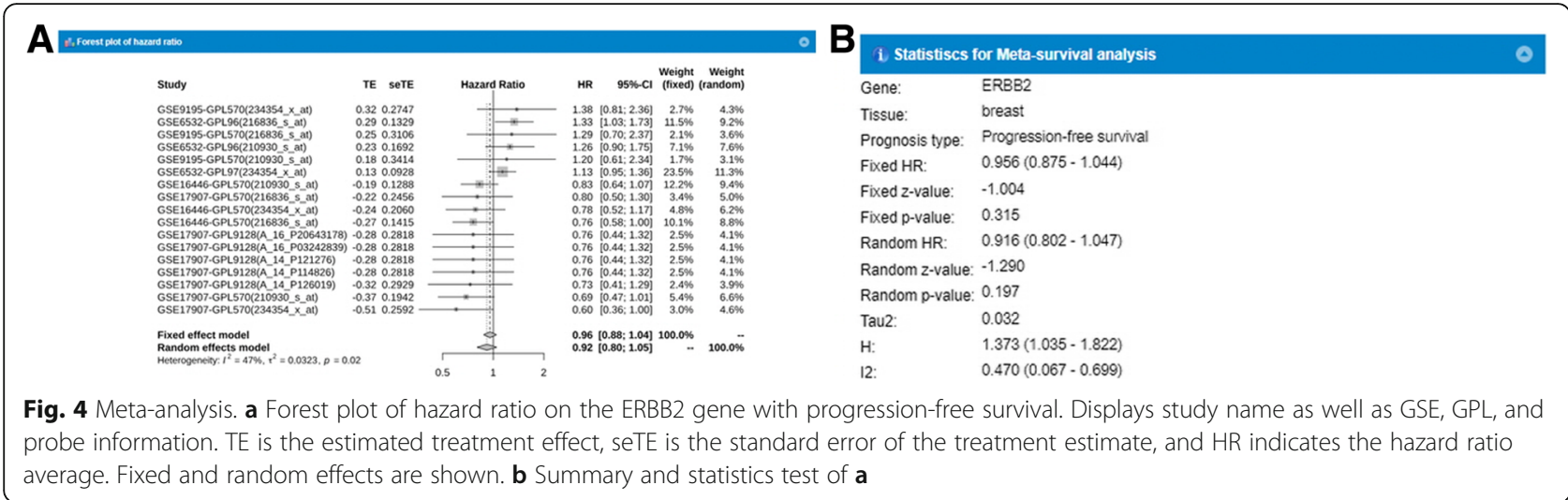

[12], CellLineNavigator [13], MERAV [14], Oncomine [15], cBioPortal [16], RNA Seq Atlas [17], KM-Express [18], BioXpress [19], TiGER [20], and so on (Table 4). Each database has its own unique advantages. First, Oncopression, CellLineNavigator, and MERAV are databases that can investigate gene profiling around the collected microarray datasets for various cancer types. Oncomine, cbioPortal, and RNA Seq Atlas are databases that analyze gene profiling for each dataset based on a microarray and RNA-sequencing. These databases have the benefit of comparing information between two high-throughput platforms. In addition, Oncomine and cBioPortal provide versatile and additional functions such as multidimensional comparison of samples (Oncomine) or integrated analysis of CNV, mutation, coexpression, and gene enrichment (cBioPortal). Lastly, the TiGER database contains EST data around several tissues. In many respects, they are very similar to GENT2 database. However, GENT2 has many useful features such as subtype analysis and meta-survival analysis, which are not available in other databases. In addition, an intuitive and user friendly interface is another advantage of GENT2 (Fig. 5). For example, the tab display in the GENT2 main page is useful when a user performs multiple iterations of analysis. In the near future, we plan to update GENT2 to enable multiple gene search and add RNA-sequencing data as well as microarrays.

\section{Conclusions}

The explosion of publicly available datasets in the cancer genomics field has provided cancer researchers invaluable resources. However, for many researchers who do not have bioinformatics skills to fully utilize the datasets, the public datasets are of little value. The widespread use of GENT since its launch at 2011 reflects the needs for carefully curated large-scale gene expression databases with an easy-to-use interface. With GENT2, we continue to provide the core functions of GENT; however, with increasing public datasets, we updated

Table 4 Comparison of GENT2 and other databases

\begin{tabular}{|c|c|c|c|c|c|c|c|}
\hline \multirow[t]{2}{*}{ Database } & \multirow[t]{2}{*}{ Data Type } & \multicolumn{3}{|c|}{ Expression profiling } & \multirow{2}{*}{$\begin{array}{l}\text { Cancer Subtype } \\
\text { profiling }\end{array}$} & \multirow{2}{*}{$\begin{array}{l}\text { Meta-survival } \\
\text { Analysis }\end{array}$} & \multirow[t]{2}{*}{ REF } \\
\hline & & Analysis Type & Cancer Type & $\begin{array}{l}\text { The number } \\
\text { of samples }\end{array}$ & & & \\
\hline GENT2 & Microarray & Aggregated & 36 & 68,140 & $\mathrm{O}$ & $\mathrm{O}$ & [1] \\
\hline Oncopression & Microarray & Aggregated & 20 & 19,000 & $x$ & $x$ & [12] \\
\hline CellLineNavigator & Microarray & Aggregated & 28 & 317 & $x$ & $x$ & [13] \\
\hline MERAV & Microarray & Aggregated & 27 & 4454 & $x$ & $x$ & [14] \\
\hline Oncomine & Microarray RNA-sequencing & Each & 20 & 86,733 & Various & $x$ & [15] \\
\hline cBioPortal & Microarray RNA-sequencing & Each & 33 & 19,360 & Various & $x$ & [16] \\
\hline RNA Seq Atlas & Microarray, RNA-sequencing & Aggregated & 16 & 113 & $x$ & $x$ & [17] \\
\hline KM-Express & RNA-sequencing & Each & 32 & 360 & Various & $x$ & [18] \\
\hline BioXpress & RNA-sequencing & Each & 23 & 6361 & $x$ & $x$ & [19] \\
\hline TiGER & expressed sequence tags & Aggregated & 30 & 13,573 & $x$ & $x$ & [20] \\
\hline
\end{tabular}

Aggregated; aggregated data presented

Each; each dataset presented 


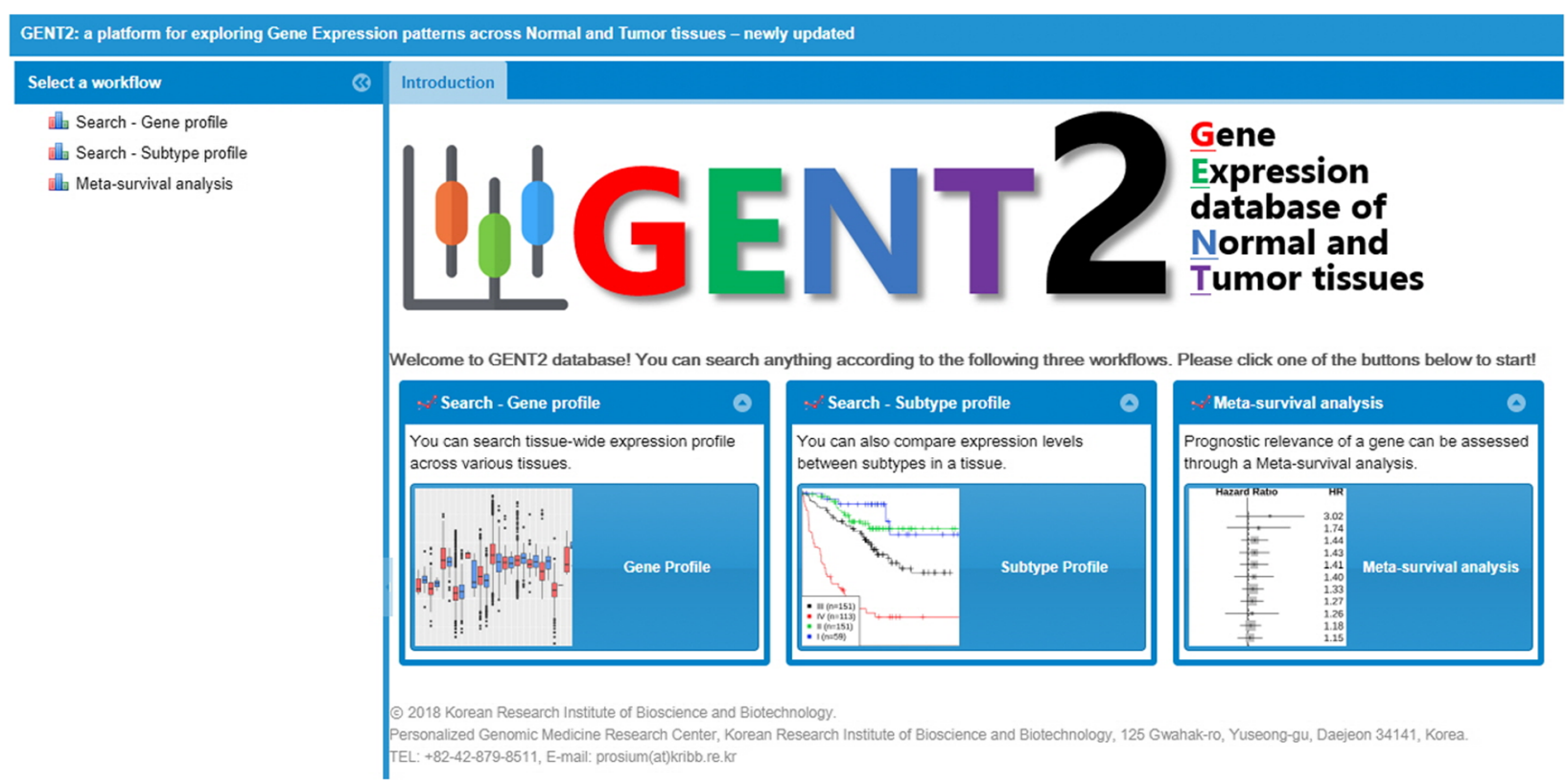

Fig. 5 User Interface. The GENT2 main page consists of three layers for user convenience. First, the left layer is used to select three functions and can be hidden by clicking the arrow button. Next, the upper layer is a tab that allows users to select each window for different analyses. Finally, the center layer is a main window for displaying analysis results such as plots and tables

and expanded the GENT database in terms of datasets and novel useful functions. The number of different tissues increased from 57 to 72 , and new functions such as subtype profiling, various statistical tests, and meta-survival analysis were added. We also adopted recent technologies such as such the GWT web framework and a Lucene indexing machine to provide more user-friendly web experiences. With those improvements in both data volume and novel functions, GENT2 will continue to be a useful tool to help researchers in the field of cancer genomics. As RNA-seq has become the de facto standard method for exploring gene expression, we plan to add gene expression datasets produced by RNA-seq in the future version of GENT.

\section{Additional files}

Additional file 1: Table S1. U133Plus2 data description in GENT2. This is the data list for the U133Plus2 platform in the GENT2 database. For Blood, more than $10 \mathrm{~K}$ samples are stored. In particular, Blood, Breast, Colon, Kidney, Skin, and Bladder tissues contain all kinds of data. (PNG 16 kb)

Additional file 2: Table S2. U133A data description in GENT2. This is the data list for the U133A platform in the GENT2 database. There are no cell-line data from U133A platform around all tissues. (PNG $16 \mathrm{~kb}$ )

Additional file 3: Figure S1. GENT2 system architecture. The GENT2 infrastructure consists of web browser and server layers. A graphical user interface (GUI) was implemented using Google Web Toolkit (GWT) and GWT extended (GXT) frameworks. Transporting data between web browser and server is controlled by GWT remote procedure call (RPC) methods. All interactions in the server layer were implemented by $\mathrm{R}$, RCaller, Apache Lucene software. (PNG 39 kb)

\section{Acknowledgements}

We thank Drs Sung-Min Park and Jong-Hwan Kim for their helpful comments on the GENT2 website and the manuscript.

\section{Funding}

Publication costs are funded by grants from the National Research Foundation of Korea (NRF-2017MBA9B5060884 and NRF-

2014M3C9A3068554), and grant from KRIBB Research Initiative Program.

Availability of data and materials

GENT2 is freely available online at http://gent2.appex.kr.

\section{About this supplement}

This article has been published as part of BMC Medical Genomics Volume 12 Supplement 5, 2019: Selected articles from the 8th Translational Bioinformatics Conference: Medical Genomics. The full contents of the supplement are available online at https://bmcmedgenomics.biomedcentral.com/articles/ supplements/volume-12-supplement-5.

\section{Authors' contributions}

SYK and SKK designed the study; SJP collected and processed data; SJP, BHY, and SKK implemented the web site. SJP, SKK, and SYK wrote the manuscript, and all authors read and approved the manuscript.

Ethics approval and consent to participate

Not applicable.

\section{Consent for publication}

Not applicable.

\section{Competing interests}

The authors declare that they have no competing interests.

\section{Publisher's Note}

Springer Nature remains neutral with regard to jurisdictional claims in published maps and institutional affiliations. 


\section{Author details}

Genome Editing Research Center, Korea Research Institute of Bioscience and Biotechnology (KRIBB), Daejeon 34141, Korea. ${ }^{2}$ Department of Bioscience, University of Science and Technology (UST), Daejeon 34113, Korea. ${ }^{3}$ Personalized Genomic Medicine Research Center, KRIBB, Daejeon 34141, Korea.

Published: 11 July 2019

\section{References}

1. Shin G, Kang TW, Yang S, Baek SJ, Jeong YS, Kim SY. GENT: gene expression database of normal and tumor tissues. Cancer Informat. 2011:10:149-57.

2. Wang $Z$, He Y, Deng $W$, Lang L, Yang $H$, Jin B, Kolhe R, Ding HF, Zhang J, Hai T, et al. Atf3 deficiency promotes genome instability and spontaneous tumorigenesis in mice. Oncogene. 2018;37(1):18-27.

3. Coebergh van den Braak RRJ, Sieuwerts AM, Kandimalla R, Lalmahomed ZS, Bril SI, van Galen A, Smid M, Biermann K, van Krieken J, Kloosterman WP, et al. High mRNA expression of splice variant SYK short correlates with hepatic disease progression in chemonaive lymph node negative colon cancer patients. PLoS One. 2017;12(9):e0185607.

4. Tsai YL, Ha DP, Zhao H, Carlos AJ, Wei S, Pun TK, Wu K, Zandi E, Kelly K, Lee AS. Endoplasmic reticulum stress activates SRC, relocating chaperones to the cell surface where GRP78/CD109 blocks TGF-beta signaling. Proc Natl Acad Sci U S A. 2018;115(18):E4245-54.

5. Dingerdissen HM, Torcivia-Rodriguez J, Hu Y, Chang TC, Mazumder R, Kahsay R. BioMuta and BioXpress: mutation and expression knowledgebases for cancer biomarker discovery. Nucleic Acids Res. 2018:46(D1):D1128-36.

6. Lee WR, Na H, Lee SW, Lim WJ, Kim N, Lee JE, Kang C. Transcriptomic analysis of mitochondrial TFAM depletion changing cell morphology and proliferation. Sci Rep. 2017;7(1):17841.

7. Gautier L, Cope L, Bolstad BM, Irizarry RA. Affy--analysis of Affymetrix GeneChip data at the probe level. Bioinformatics. 2004;20(3):307-15.

8. Cancer Genome Atlas N. Comprehensive molecular portraits of human breast tumours. Nature. 2012;490(7418):61-70.

9. Day KC, Lorenzatti Hiles G, Kozminsky M, Dawsey SJ, Paul A, Broses L, Shah R, Kunja LP, Hall C, Palanisamy N, et al. HER2 and EGFR overexpression support metastatic progression of prostate cancer to bone. Cancer Res. 2017;77(1):74-85

10. Loi S, Haibe-Kains B, Desmedt C, Wirapati P, Lallemand F, Tutt AM, Gillet C, Ellis $\mathrm{P}$, Ryder $\mathrm{K}$, Reid JF, et al. Predicting prognosis using molecular profiling in estrogen receptor-positive breast cancer treated with tamoxifen. BMC Genomics. 2008:9:239.

11. Desmedt C, Di Leo A, de Azambuja E, Larsimont D, Haibe-Kains B, Selleslags J, Delaloge S, Duhem C, Kains JP, Carly B, et al. Multifactorial approach to predicting resistance to anthracyclines. J Clin Oncol. 2011; 29(12):1578-86.

12. Lee J, Choi C. Oncopression: gene expression compendium for cancer with matched normal tissues. Bioinformatics. 2017:33(13):2068-70.

13. Krupp M, Itzel T, Maass T, Hildebrandt A, Galle PR, Teufel A. CellLineNavigator: a workbench for cancer cell line analysis. Nucleic Acids Res. 2013;41(Database issue):D942-8.

14. Shaul YD, Yuan B, Thiru P, Nutter-Upham A, McCallum S, Lanzkron C, Bell GW, Sabatini DM. MERAV: a tool for comparing gene expression across human tissues and cell types. Nucleic Acids Res. 2016;44(D1): D560-6.

15. Rhodes DR, Yu J, Shanker K, Deshpande N, Varambally R, Ghosh D, Barrette T, Pandey A, Chinnaiyan AM. ONCOMINE: a cancer microarray database and integrated data-mining platform. Neoplasia. 2004;6(1):1-6.

16. Gao J, Aksoy BA, Dogrusoz U, Dresdner G, Gross B, Sumer SO, Sun Y, Jacobsen A, Sinha R, Larsson E, et al. Integrative analysis of complex cancer genomics and clinical profiles using the cBioPortal. Sci Signal. 2013;6(269):pl1.

17. Krupp M, Marquardt JU, Sahin U, Galle PR, Castle J, Teufel A. RNA-Seq Atlas-a reference database for gene expression profiling in normal tissue by nextgeneration sequencing. Bioinformatics. 2012;28(8):1184-5.
18. Chen X, Miao Z, Divate M, Zhao Z, Cheung E. KM-express: an integrated online patient survival and gene expression analysis tool for the identification and functional characterization of prognostic markers in breast and prostate cancers. Database. 2018;2018.

19. Wan Q, Dingerdissen H, Fan Y, Gulzar N, Pan Y, Wu TJ, Yan C, Zhang H, Mazumder R. BioXpress: an integrated RNA-seq-derived gene expression database for pan-cancer analysis. Database. 2015;2015.

20. Liu X, Yu X, Zack DJ, Zhu H, Qian J. TiGER: a database for tissue-specific gene expression and regulation. BMC Bioinformatics. 2008;9:271.
Ready to submit your research? Choose BMC and benefit from:

- fast, convenient online submission

- thorough peer review by experienced researchers in your field

- rapid publication on acceptance

- support for research data, including large and complex data types

- gold Open Access which fosters wider collaboration and increased citations

- maximum visibility for your research: over $100 \mathrm{M}$ website views per year

At $\mathrm{BMC}$, research is always in progress.

Learn more biomedcentral.com/submissions 